\title{
ACÚMULO DE NUTRIENTES EM MUDAS DE ACEROLEIRA ADUBADAS COM FÓSFORO E ZINCO ${ }^{1}$
}

\author{
FERNANDO LUIZ DE OLIVEIRA CORRÊA², CARLOS ALBERTO SPAGGIARI SOUZA ${ }^{3}$, VANDER MENDONÇA ${ }^{4}$, \\ JANICE GUEDES DE CARVALHO 5
}

\begin{abstract}
RESUMO - Objetivando estudar o efeito de doses de fósforo e de zinco no acúmulo de nutrientes na folha e no caule de aceroleira (Malpighia glabra L.), montou-se um experimento em casa de vegetação, localizada no pomar da Universidade Federal de Lavras-UFLA, utilizando-se de mudas oriundas de sementes. O delineamento experimental utilizado foi blocos casualizados, em esquema fatorial 4 x 3, constituído de 2 plantas por parcela, com 4 repetições. Os fatores consistiram de 4 doses de fósforo $\left(0 ; 150 ; 300\right.$ e $\left.450 \mathrm{mg} \mathrm{dm}^{-3} \mathrm{de} \mathrm{P}\right)$, na forma de superfosfato triplo e o zinco nas doses ( 0 ; 5 e 10 $\mathrm{mg} \mathrm{dm}{ }^{-3} \mathrm{de} \mathrm{Zn}$ ), na forma de sulfato de zinco. Após 100 dias, as mudas foram colhidas, sendo avaliadas as quantidades acumuladas de $\mathrm{N}, \mathrm{P}, \mathrm{K}, \mathrm{Ca}, \mathrm{Mg}$, $\mathrm{S}, \mathrm{B}, \mathrm{Cu}, \mathrm{Zn}$ e Mn na matéria seca de folha e caule. A interação entre os nutrientes fósforo e zinco afetou positivamente nos acúmulos de Ca, Cu, Fe e Mn na matéria seca da folha de aceroleira, sendo os acúmulos dos demais nutrientes afetados positivamente pelo fósforo. O Zn só teve efeito positivo no acúmulo de zinco na matéria seca do caule. A dose $450 \mathrm{mg} \mathrm{dm}^{-3} \mathrm{de} \mathrm{P}$ proporcionou aumento no acúmulo de todos os nutrientes na folha e caule das mudas de aceroleira.
\end{abstract}

Termos para indexação: Acerola, Malpighia glabra L., propagação e nutrição.

\section{NUTRIENTS ACCUMULATION IN THE ACEROLA FRUIT TREE SEEDLINGS FERTILIZER WITH PHOSPHORUS AND ZINC}

\begin{abstract}
An experiment was conducted under greenhouse conditions at Lavras Federal University Lavras, in order to verify the effect of P and $\mathrm{Zn}$ rates in the amount of nutrients at the leaves and the stem of acerola fruit tree (Malpiglia glabra $\mathrm{L}$.) seedling. The experimental delineation was in randomized blocks, in a 2 factors design ( $4 \times 3$ ), with 4 replications per treatment, with 2 plants per plot. The seedlings were submitted to four different rates of $\mathrm{P}\left(0,150,300\right.$ and $450 \mathrm{mg} \mathrm{dm}^{-3}$ of soil) obtained from Triple superphosphate and three rates of $\mathrm{Zn}\left(0,5\right.$ and $10 \mathrm{mg} \mathrm{dm}^{-3}$ of soil) obtained from Zinc sulphate. After 100 days, the seedlings were harvested and the quantity of $\mathrm{N}, \mathrm{P}, \mathrm{K}, \mathrm{Ca}, \mathrm{Mg}, \mathrm{S}, \mathrm{B}, \mathrm{Cu}, \mathrm{Zn}$ and $\mathrm{Mn}$ in the dry matter of the leaves and stem was evaluated. The interaction of $\mathrm{P}$ and $\mathrm{Zn}$ presented a significant effect over the amount of $\mathrm{Ca}, \mathrm{Cu}, \mathrm{Fe}$ and $\mathrm{Mn}$ at the leaves dry matjer and the other nutrients amount were affected by the P. The $\mathrm{Zn}$ affected only the amount of $\mathrm{Zn}$ in the stem dry mather. The largest amount of all nutrients at the leaves and the stem was obtained by using $450 \mathrm{mg} \mathrm{P} \mathrm{dm}^{-3}$ of soil.
\end{abstract}

Index Terms: Acerola, Malpighia glabra L., propagation and fertilization.

\section{INTRODUÇÃo}

Em função de seu altíssimo teor de vitamina C e da importância dessa vitamina na medicina mundial, a aceroleira (Malpighia glabra L.) é hoje, em termos relativos e com tendência a expansão, uma das principais culturas de exportação da fruticultura brasileira. Está sendo consumida, de forma crescente, principalmente pelos japoneses, europeus e norte-americanos. No Brasil, destacam-se as regiões Norte e Nordeste como as principais produtoras desta fruta, e os Estados da Bahia e Pernambuco ocupam a primeira e segunda posições, respectivamente (Tittoto et al., 1998).

A propagação da aceroleira pode ser feita com emprego de sementes, estaquia ou enxertia ( Marty \& Pennock, 1965; Amaral, 1992). Por meio de sementes, é bastante utilizada, pois, sendo a aceroleira uma planta autofértil, podem-se obter plantas praticamente idênticas (Simão, 1971). Porém, em plantio em grande escala, essa modalidade de propagação requer que as sementes sejam provenientes de frutos colhidos em área formada com plantas uniformes, portadoras das melhores características produtivas e comerciais, pois, desse modo, reduz-se o risco da geração de matrizes geneticamente indesejáveis (Gonzaga Neto \& Soares, 1994).

Apesar de a aceroleira ser uma planta rústica, facilmente adaptável aos mais variados tipos de solo, ela requer um manejo correto da adubação e nutrição das plantas, principalmente em pomares orientados para exportação (Gonzaga Neto \& Soares, 1994).

Com relação a estudos sobre nutrição e adubação mineral da aceroleira, poucos trabalhos têm sido citados na literatura. Estes restringem-se apenas à composição química de nutrientes nos frutos e à parte vegetativa da planta adulta em fase produtiva (Alves, 1987).

Os primeiros estudos referentes à interação entre o fósforo e o zinco iniciaram-se por volta de 1936, sendo bastante destacada nos trabalhos de Olsen (1972). Este mesmo autor relata que diversas causas estão envolvidas na caracterização da interação entre o fósforo e o zinco, destacando-se quatro possíveis causas como as mais relevantes: a) a interação P e Zn no solo; b) a diminuição da taxa de translocação do zinco para a parte aérea; c) simples "efeito de diluição" sobre a concentração de Zn na parte aérea devido ao crescimento em resposta à adição de fósforo, principalmente quando o solo é pobre em fósforo e zinco; e d) desordem metabólica no interior das células da planta, relacionada ao desequilíbrio entre fósforo e zinco, ou à excessiva concentração de fósforo, que interferiria na função metabólica do zinco em certos sítios celulares.

O problema da interação entre o fósforo e o zinco tornou-se bastante preocupante, principalmente nas regiões originalmente sob vegetação de cerrado, onde a ocorrência de deficiências de fósforo e de zinco são bastante comuns. A adubação fosfatada é convencional e a recomendação de adição de zinco às fórmulas de adubação está tornando-se rotina nestas regiões (Oliveira, 2000).

A interação entre o fósforo e o zinco influenciou positivamente nas características de crescimento: matéria seca da folha, diâmetro do caule e altura da muda, bem como na sua nutrição, proporcionando aumento nas quantidades acumuladas dos nutrientes na matéria seca da parte aérea e das raízes de mudas de maracujazeiro-amarelo e na nutrição de mudas de mamoeiro, tendo efeito positivo sobre as características de crescimento: matéria seca da folha, diâmetro do caule e altura da muda, bem como aumentos nos acúmulos de $\mathrm{P}, \mathrm{Ca}, \mathrm{S}, \mathrm{B}$ e Zn no caule e $\mathrm{P}, \mathrm{K}, \mathrm{Ca}$,

1 (Trabalho 007/2002). Recebido: 19/01/2002. Aceito para publicação: 02/05/2002.

2 Eng. Agrônomo, M. Sc. Doutorando UFLA-Lavras/MG e Pesquisador da Comissão Executiva do Plano da Lavoura Cacaueira/Estação Exp. de Ouro Preto, Ouro Preto do Oeste- RO, CP 11 Fone (0xx35)3821-1929 E-mail floc@ufla.br

3 Eng. Agrônomo, Dr. Prof. Visitante do Departamento de Agricultura-UFLA, Cx. Postal 137CEP 37200-000 Lavras-MG Fone (0xx35)3821-2851 E-mail casouza@ufla.br.

4 Eng. Agrônomo M.Sc. Doutorando-UFLA, Cx. Postal 137 Lavras-MG, CEP 37200-000 Fone (0xx35)3822-5210 E-mail vander@ufla.br

5 Eng. Agrônoma, Dra. Prof ${ }^{a}$. Titular, Depto de Solos - UFLA, Cx. Postal 137 CEP 37200-000 Lavras-MG,CEP 37200-000 Fone (0xx35) 3829-1269 E-mail janicegc@ufla.br 
Mg, S, B, Cu e Zn nas folhas (Machado, 1998; Oliveira, 2000).

A aplicação de doses de superfosfato simples $(3,0 ; 6,0$ e $9,0 \mathrm{~kg}$ $\mathrm{m}^{-3} \mathrm{de}$ solo) na formação de mudas de maracujazeiro-amarelo proporcionou acréscimos nos teores de nitrogênio, potássio e magnésio na matéria seca da parte aérea em relação à ausência do fósforo (Peixoto, 1986).

Conduziu-se este experimento em Lavras-MG, no período de junho a setembro de 1996, com o objetivo de avaliar o acúmulo de macro e micronutrientes na matéria seca da folha e caule, em mudas de aceroleira adubadas com fósforo e zinco.

\section{MATERIALEMÉTODOS}

O experimento foi instalado em casa de vegetação situada no pomar do Departamento de Agricultura da Universidade Federal de Lavras (UFLA), em Lavras-MG, nos meses de julho a setembro de 1996. A cidade de Lavras está situada a $21^{\circ} 14^{\prime} 06^{\prime \prime}$ de latitude Sul e $45^{\circ} 00^{\prime} 00^{\prime \prime}$ de longitude Oeste, e a uma altitude média de 913 metros. De acordo com Vilela e Ramalho (1979), adotando-se os critérios propostos por Köeppen, o clima da região é de transição entre $\mathrm{Cwb}$ e Cwa, temperatura suave (mesotérmico), caracterizado por inverno seco, com verãos brandos e chuvosos, também denominado clima tropical de altitude.

O material utilizado constou de sementes de frutos maduros oriundos de pomar comercial localizado na região. Após a retirada dos frutos, as sementes foram lavadas e semeadas em canteiros com areia lavada e, posteriormente, repicadas para vasos com capacidade de $2 \mathrm{dm}$ ${ }^{3}$, sendo colocado $1 \mathrm{~kg}$ do solo em cada vaso, utilizando-se, como substrato, de amostras de solo da camada de 0-20 cm de um Latossolo Roxo coletadas no município de Lavras-MG. Após análise do solo, cujos resultados da análise química se encontram na Tabela 1, efetuou-se a correção do $\mathrm{pH}$ para 50\% de saturação por bases, conforme descrito por Quaggio (1983), usando-se carbonato de cálcio e de magnésio p.a., na relação 4:1. A calagem foi efetuada 20 dias antes da repicagem das mudas.

TABELA 1 - Resultado da análise química do solo da camada de 0-20 cm do solo utilizado no experimento com aceroleira em Lavras-MG, realizado pelo Laboratório de Fertilidade do Solo da UFLA- Lavras-MG, 1996.

\begin{tabular}{|c|c|c|c|c|c|c|c|c|c|c|c|c|c|c|c|c|}
\hline $\mathrm{pH}$ & $\mathrm{P}$ & $\mathrm{K}$ & $\mathrm{Ca}$ & $\mathrm{Mg}$ & $\mathrm{Al}$ & $\mathrm{H}+\mathrm{Al}$ & SB & $\mathrm{t}$ & $\mathrm{T}$ & $\mathrm{m}$ & $\mathrm{V}$ & C & M.0. & $S$ & $\mathrm{~B}$ & $\mathrm{Zn}$ \\
\hline $\mathrm{H}_{2} \mathrm{O}$ & $\mathrm{Mg} /$ & & & & & $101 / \mathrm{dn}$ & & & & & $\%$ & & dag $/ \mathrm{Kg}$ & \multicolumn{3}{|c|}{$\mathrm{Mg} / \mathrm{dm}^{3}$} \\
\hline 5,0 & 2,0 & 16 & 8,0 & 4,0 & 1,0 & 2,3 & 12 & 13 & 35 & 7 & 35 & 0,7 & 1,2 & 6,38 & 0,08 & \begin{tabular}{|l|l}
0,8 \\
\end{tabular} \\
\hline
\end{tabular}

pH em água, $\mathrm{KCl}$ e $\mathrm{CaCl}_{2}$ - Relação 1:2,5; P-K-Zn - Extrator Mehlich 1; H+Al - Extrator: SMP; Ca-Mg-Al - Extrator: KCl; B-Extrator - Extrator em água quente; S-Extrator - Fosfato monocálcio em ác. acético

O delineamento utilizado foi em blocos casualizados, em esquema fatorial $4 \times 3$, com duas plantas por parcela e quatro repetições, totalizando 96 plantas. Os fatores consistiram das seguintes doses de fósforo $\left(0 ; 150 ; 300\right.$ e $\left.450 \mathrm{mg} \mathrm{dm}^{-3} \mathrm{de} \mathrm{P}\right)$, aplicadas na forma de superfosfato triplo e de zinco $\left(0 ; 5\right.$ e $10 \mathrm{mg} \mathrm{dm}^{-3} \mathrm{de} \mathrm{Zn}$ ), na forma de sulfato de zinco. O superfosfato triplo foi finamente moído em gral e misturado ao solo, até completa homogeneização. O sulfato de zinco foi dissolvido na água e aplicado via solução.

Os demais nutrientes a as doses empregadas foram: $\mathrm{N}(400 \mathrm{mg}$ $\left.\mathrm{dm}^{-3}\right) ; \mathrm{K}\left(200 \mathrm{mg} \mathrm{dm}^{-3}\right) ; \mathrm{Mg}\left(36,0 \mathrm{mg} \mathrm{dm}^{-3}\right) ; \mathrm{Cu}\left(1,5 \mathrm{mg} \mathrm{dm}^{-3}\right) ; \operatorname{Mo}(0,1 \mathrm{mg}$ $\left.\mathrm{dm}^{-3}\right)$; e $\mathrm{B}\left(0,5 \mathrm{mg} \mathrm{dm}^{-3}\right)$. Os nutrientes $\mathrm{N}$ e $\mathrm{K}$ foram aplicados parceladamente em 4 doses, sendo a primeira na repicagem das mudas e as demais aos 30; 60 e 90 dias. Como fontes de $\mathrm{N}$, foram utilizados o sulfato de amônio e a uréia, alternadamente, e a fonte de $\mathrm{K}$ usada foi o cloreto de potássio.

A umidade nos vasos foi mantida em torno de $60 \%$ do V.T.P. (volume total de poros), com aplicações de água desmineralizada, sendo o controle efetuado por pesagens diárias dos vasos.

Após cem dias da repicagem das mudas, as plantas foram colhidas e, em seguida, foram colocadas para secar em estufas a $60^{\circ} \mathrm{C}$, até a obtenção do peso constante. Posteriormente, procederam-se a pesagem da matéria seca do caule e folhas, trituração do caule e das folhas, separadamente, e determinou-se o acúmulo dos nutrientes: $\mathrm{N}, \mathrm{P}$, $\mathrm{K}, \mathrm{Ca}, \mathrm{Mg}, \mathrm{S}, \mathrm{B}, \mathrm{Cu}, \mathrm{Fe}$, Mn e Zn, conforme metodologia proposta por Malavolta et al. (1989) Os extratos da matéria seca dos tecidos foram obtidos mediante digestão nitroperclórica, exceto para o boro, que foi por incineração da amostra e determinação por colorimetria (método da curcumina). As concentrações dos outros elementos foram assim determinadas: $\mathrm{Ca}, \mathrm{Mg}, \mathrm{Cu}, \mathrm{Mn}, \mathrm{Zn}$ e Fe por espectrofotometria de absorção atômica, $\mathrm{P}$ por colorimetria, $\mathrm{K}$ por fotometria de chama, $\mathrm{S}$ por turbidimetria. Os teores de $\mathrm{N}$ foram determinados pelo método semimicro Kjeldahl.

\section{RESULTADOSE DISCUSSÃO}

Observa-se, na Figura 1, um efeito linear crescente das doses de $\mathrm{P}$ no acúmulo de nitrogênio no caule e folha, sendo o acúmulo de nitrogênio na folha relativamente maior que no caule, em todas as doses de fósforo.

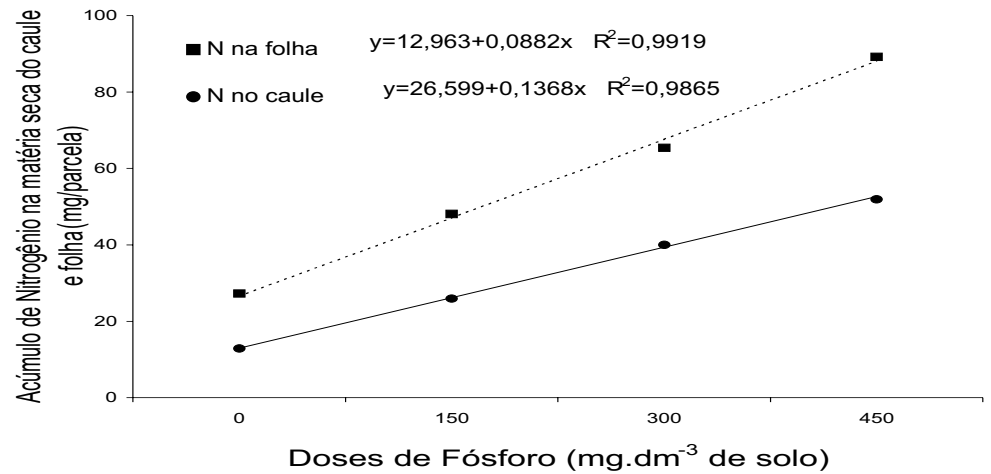

FIGURA 1 - Quantidade de N acumulada na matéria seca no caule e folha de mudas de aceroleira. Lavras, UFLA. 1996.

Marques (1990) e Barbosa (1994) também encontraram respostas ao fósforo, cuja ação isolada influenciou nas concentrações de nitrogênio no caule, respectivamente, em mudas de seringueira e aroeirado-sertão, demonstrando a diferença comportamental na exigência nutricional entre espécies.

Para Malavolta (1980), a alta taxa de quantidades acumuladas de nitrogênio está correlacionada diretamente ao desenvolvimento vegetativo em plantas novas, isto porque os processos de multiplicação e diferenciação celulares mantêm-se sempre em fluxos contínuos.

As quantidades acumuladas de fósforo na folha e caule de mudas de aceroleira foram crescentes em resposta às aplicações deste nutriente (Figura 2), e a resposta ajustou-se a modelo com comportamento também linear, o qual permite relatar que a dose de $450 \mathrm{mg} \mathrm{dm}^{-3} \mathrm{de}$ $\mathrm{P}$ foi a que proporcionou os maiores acúmulos de fósforo. Ainda na Figura 2, observa-se também o efeito linear crescente das doses de fósforo no acúmulo de enxofre na folha e caule, sendo o maior acúmulo deste nutriente na folha $\left(4,68 \mathrm{mg} \cdot\right.$ parcela $\left.^{-1}\right)$ e caule $\left(1,77 \mathrm{mg} \cdot\right.$ parcela $\left.^{-1}\right)$ apresentado na dose de $450 \mathrm{mg} \mathrm{dm}^{-3}$ de $\mathrm{P}$.

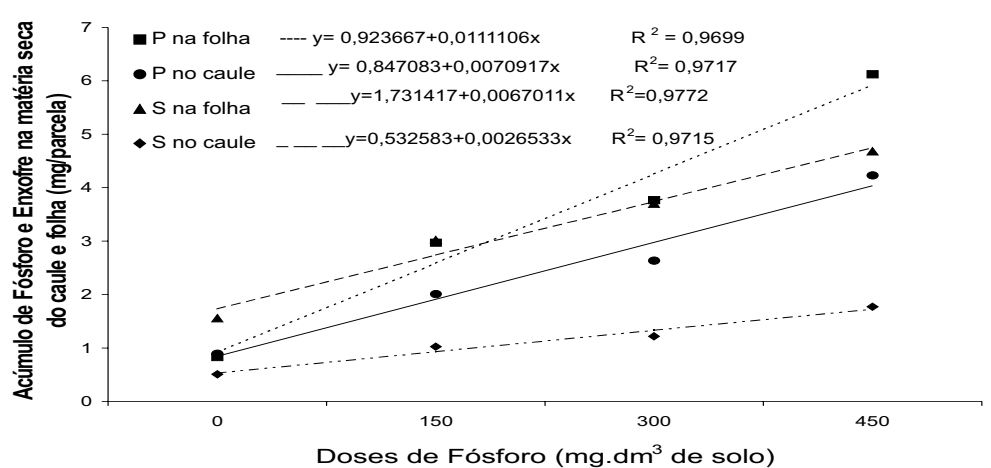

FIGURA 2 - Quantidade de P e S acumulada na matéria seca do caule e folha de mudas de aceroleira. Lavras, UFLA. 1996 
Estes acréscimos nos teores de fósforo na matéria seca de folhas e caules da aceroleira foram proporcionados pelas crescentes adições do mesmo no substrato solo, aumentado sua disponibilidade na solução do solo, favorecendo assim uma maior absorção pelas raízes, ocasionando aumentos deste nutriente nos órgãos da planta.

Na Figura 3, observa-se que o acúmulo de potássio na matéria seca da folha e caule teve suas equações de regressão ajustadas a modelos de comportamento linear crescente, independentemente das doses de zinco, em relação às doses de fósforo. $\mathrm{O}$ maior acúmulo de $\mathrm{K}$ no caule $\left(44,12 \mathrm{mg} \mathrm{parcela}^{-1}\right)$ e na folha $\left(46,41 \mathrm{mg}\right.$ parcela $\left.^{-1}\right)$ foi na dose de $450 \mathrm{mg} \mathrm{dm}^{-3} \mathrm{de}$ P, resultados estes que se assemelham aos de Barbosa (1994), Machado (1998) e Oliveira (2000) com mudas de aroeira-do-sertão, maracujazerio e mamoeiro, respectivamente.

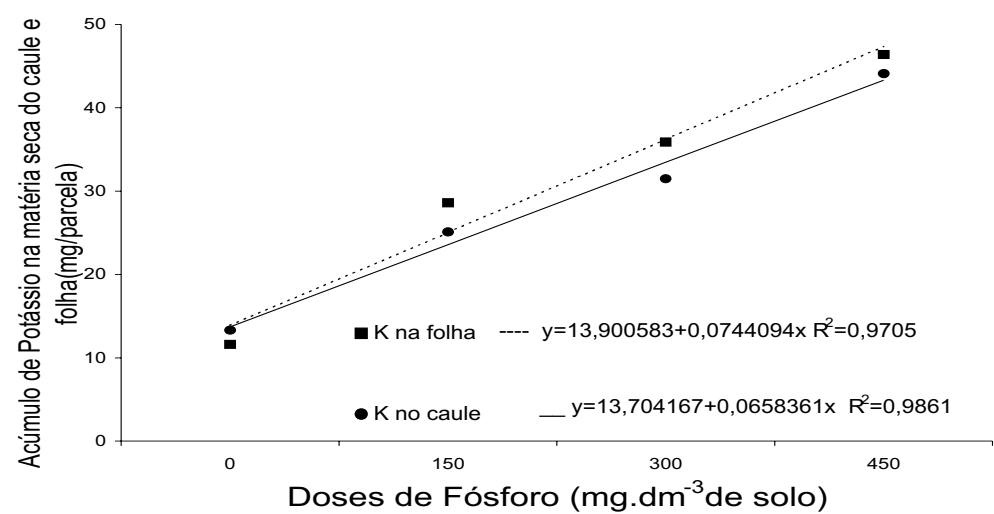

FIGURA 3 - Quantidade de K acumulada na matéria seca do caule e folha de mudas de aceroleira. Lavras, UFLA. 1996

Este aumento no acúmulo de potássio pode caracterizar em parte um consumo de luxo, provavelmente pelas altas concentrações de fósforo na solução do solo, o qual em parte ficaria indisponível, favorecendo a absorção de potássio, trazendo resistência das mudas ao acamamento.

As respostas do acúmulo de Ca na folha e caule são apresentadas na Figura 4, na qual se observa que, na folha, houve interação entre $\mathrm{P}$ e Zn para o acúmulo de $\mathrm{Ca}$, com um comportamento linear e, no caule, resposta significativa apenas para as doses de fósforo. O maior acúmulo de Ca na folha (43,75 $\mathrm{mg} \mathrm{parcela}^{-1}$ ) foi alcançado na dose de $0 \mathrm{mg} \mathrm{dm}^{-3} \mathrm{de}$ Zn e $450 \mathrm{mg} \mathrm{dm}^{-3}$ de $\mathrm{P}$, e o menor acúmulo $\left(4,23 \mathrm{mg}\right.$ parcela $\left.^{-1}\right)$ foi na dose de $0 \mathrm{mg} \mathrm{dm}^{-3}$ de $\mathrm{Zn} \mathrm{e} 0 \mathrm{mg} \mathrm{dm}^{-3} \mathrm{de}$ P. No caule, o acúmulo só foi influenciado pelas doses de fósforo, sendo a melhor resposta para o acúmulo de $\mathrm{Ca}\left(25,54 \mathrm{mg}_{\text {parcela }}{ }^{-1}\right)$ na dose de $450 \mathrm{mg} \mathrm{dm}^{-3} \mathrm{de} \mathrm{P}$.

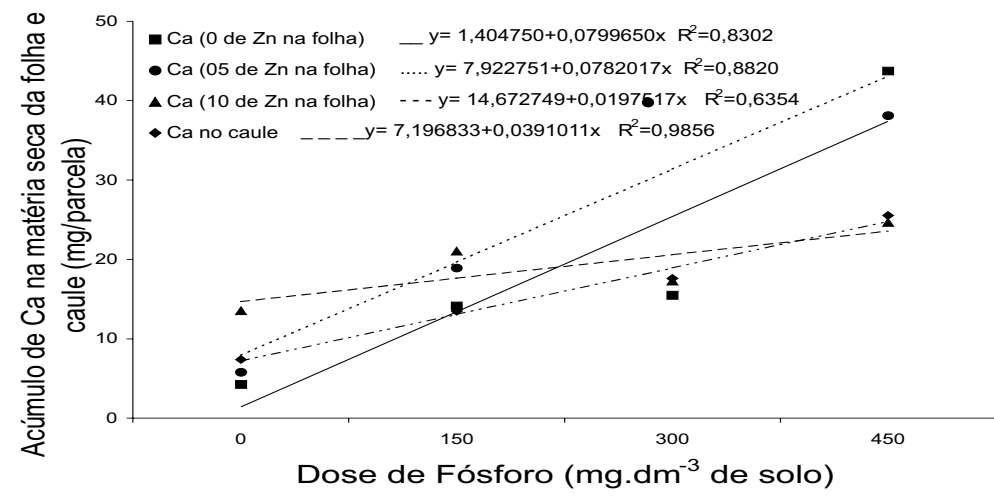

FIGURA 4 - Quantidade de Ca acumulada na matéria seca do caule e folha de mudas de aceroleira. Lavras, UFLA. 1996

O aumento da quantidade acumulada de cálcio pode ser em parte explicado pela aplicação no solo do superfosfato triplo, o qual contém, em sua composição química, em torno de $13 \%$ de cálcio, podendo assim ter contribuído para o aumento dos teores do mesmo na solução do solo.

Estes resultados assemelham-se aos encontrados por Oliveira (2000) que, aplicando as mesmas doses de P e Zn em mudas de mamoeiro, encontrou interação destes nutrientes na quantidade acumulada de cálcio na matéria seca da folha. Porém, no caule, este mesmo autor encontrou interação $\mathrm{Pe} \mathrm{Zn}$ num comportamento quadrático para o acúmulo de cálcio no caule. Marques (1990) também detectou respostas somente com as aplicações do fósforo no acúmulo de cálcio na matéria seca do caule em mudas de seringueira.

Verificou-se que as quantidades acumuladas de magnésio na matéria seca da folha e caule (Figura 5) sofreram variações em função apenas das doses de fósforo, que apresentou um ajuste com comportamento linear crescente, com a melhor resposta para o acúmulo de magnésio na folha ( $\left.14,59 \mathrm{mg}_{\text {parcela }}{ }^{-1}\right)$ e caule $\left(4,64 \mathrm{mg}_{\text {parcela }}{ }^{-1}\right)$ quando se aplicou a dose de $450 \mathrm{mg} \mathrm{dm}^{-3}$ de P. Este nutriente é de suma importância no desenvolvimento e na produção para as plantas, pois, além de estar diretamente relacionado ao nutriente fósforo e ao metabolismo energético dos vegetais, é um dos componentes da molécula de clorofila (Malavolta, 1980).

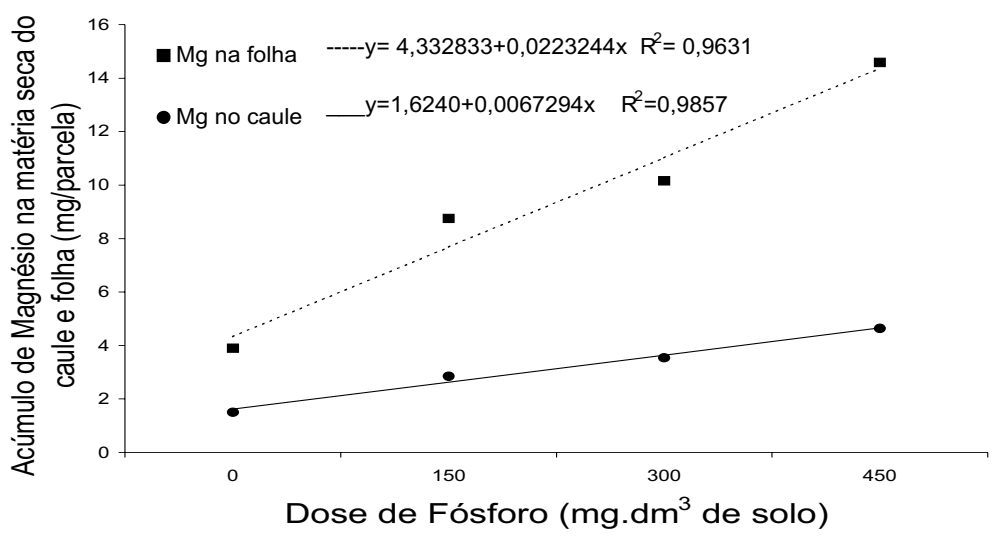

FIGURA 5 - Quantidade de Mg acumulada na matéria seca do caule e folha de mudas de aceroleira. Lavras, UFLA. 1996

As quantidades acumuladas de boro na folha e caule foram influenciadas apenas pelas doses de fósforo, que apresentou um efeito também linear crescente com o maior acúmulo na folha $(166,97 \mu \mathrm{g}$ parce$\mathrm{la}^{-1}$ ) e caule (186,34 $\mu \mathrm{g}$ parcela ${ }^{-1}$ ) na dose de $450 \mathrm{mg} \mathrm{dm}^{-3} \mathrm{de} P$ (Figura 6). Este maior acúmulo de boro no caule deve-se ao seu efeito não competitivo à absorção de zinco, aumentando a sua concentração na solução do solo e, conseqüentemente, diminuindo a do fósforo (Malavolta et al., 1989).

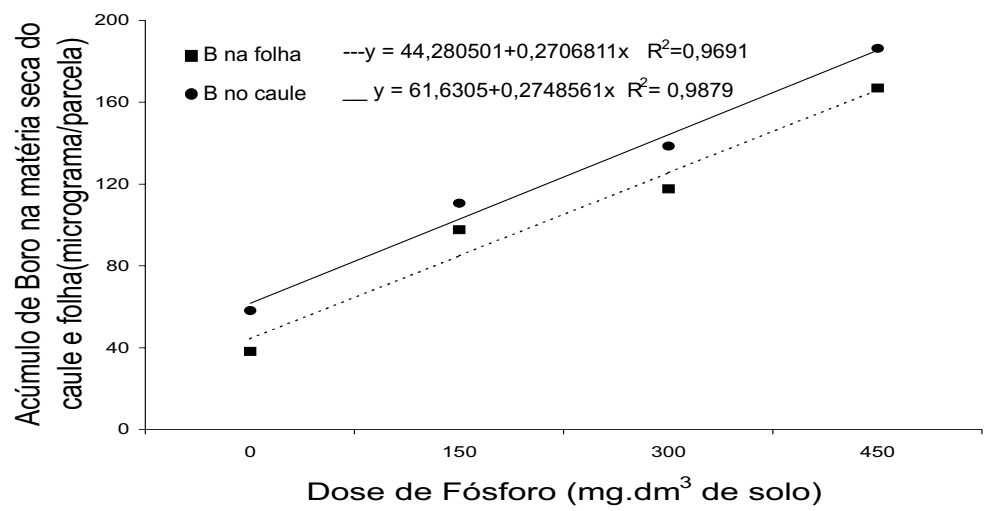

FIGURA 6 - Quantidade de B acumulada na matéria seca do caule e folha de mudas de aceroleira. Lavras, UFLA. 1996

O comportamento das quantidades acumuladas de cobre na matéria seca da folha e caule é apresentado na Figura 7. Observa-se que o acúmulo de cobre, tanto na folha como no caule, ajusta-se de maneira linear, e a dose de $450 \mathrm{mg} \mathrm{dm}^{-3}$ de $\mathrm{P}$ é a que proporcionou os maiores acúmulos de cobre nas mudas de aceroleiras. Estes resultados discordam dos encontrados por Barbosa (1994), Machado (1998) e Oliveira (2000), os quais detectaram a influência da interação entre doses de fósforo e zinco nas quantidades acumuladas de cobre em diversas partes das plantas: aoreira-do-sertão, maracujazeiro-amarelo e mamoeiro, respetivamente, denotando que as plantas que apresentarem maior taxa de crescimento, apresentarão maior conteúdo de cobre na matéria seca. 


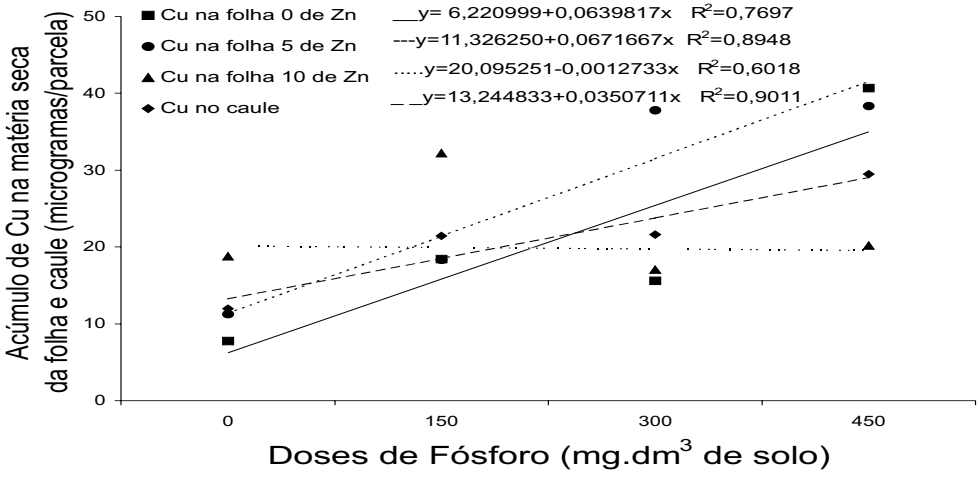

FIGURA 7 - Quantidade de $\mathrm{Cu}$ acumulada na matéria seca do caule e folha de mudas de aceroleira. Lavras, UFLA. 1996

Nas Figuras 8 e 9, são apresentadas as respostas das quantidades acumuladas de ferro e zinco, nas quais observa que o ferro acumulado na matéria seca da folha foi influenciado pela interação fósforo e zinco. Já o acúmulo de zinco na matéria seca da folha foi influenciado pelas doses de fósforo e, na matéria seca do caule, pelas doses de fósforo e zinco que apresentou um efeito também linear (Figura 9). Estas respostas indicam que a absorção de zinco pelas plantas foi afetada pelas dose de $\mathrm{P}$, o que concorda com as observações encontradas por Barbosa (1994), que pode ser explicada pelo "efeito de diluição" de zinco, como conseqüência do maior crescimento da planta em resposta ao fósforo.

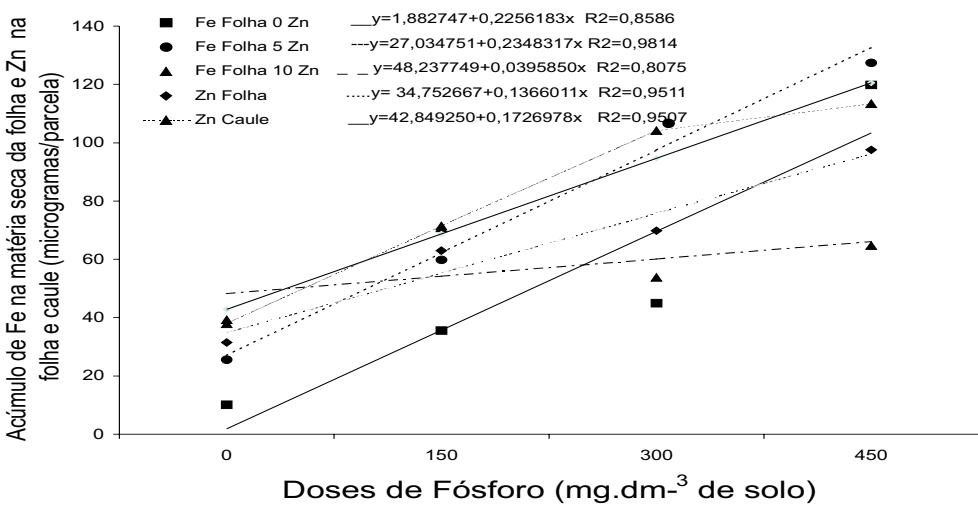

FIGURA 8 - Quantidade de Fe e Zn acumulada na matéria seca do caule e folha de mudas de aceroleira. Lavras, UFLA. 1996.

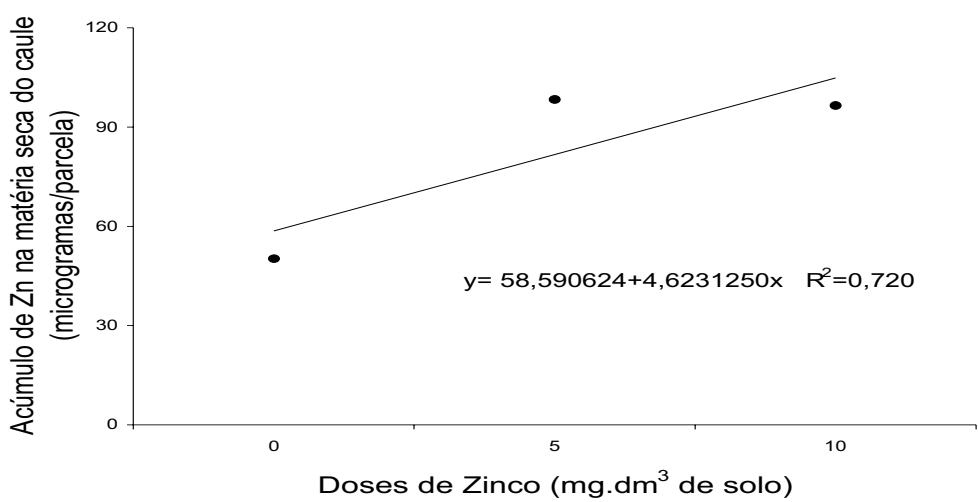

FIGURA 9 - Quantidade de Zn acumulada na matéria seca do caule e folha de mudas de aceroleira. Lavras, UFLA. 1996.

Com relação ao manganês (Figura 10), observa-se que, para o acúmulo na matéria seca da folha, houve influência da interação fósforo e zinco, sendo o maior acúmulo $\left(388,59 \mu \mathrm{g}_{\text {parcela }}{ }^{-1}\right)$ observado na dose de $450 \mathrm{mg} \mathrm{dm}^{-3}$ de $\mathrm{P}$ e $0 \mathrm{mg} \mathrm{dm}{ }^{-3}$ de $\mathrm{Zn}$. Já o acúmulo no caule foi influenciado apenas pelas doses de fósforo, com a melhor resposta para o acúmulo de manganês na dose de $450 \mathrm{mg} \mathrm{dm}^{-3} \mathrm{de} P$.

A dose máxima de fósforo usada, $450 \mathrm{mg} \mathrm{dm}^{-3} \mathrm{de} \mathrm{P}$, parece ter sido insuficiente para interferir sobre o acúmulo da maioria dos nutrientes estudados, uma vez que a maioria dos nutrientes apresentaram comportamento linear crescente. Porém, foi nesta dose que as mudas tiveram maior desenvolvimento em altura, diâmetro do caule, número de folhas, massa seca de raiz e massa seca de parte aérea (Tabela 1).

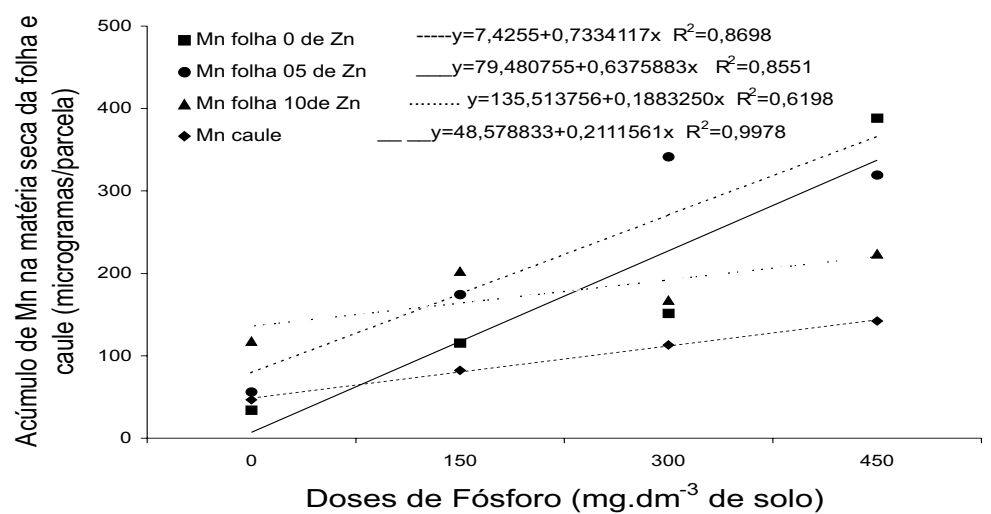

FIGURA 10 - Quantidade de Mn acumulada na matéria seca do caule e folha de mudas de aceroleira. Lavras, UFLA. 1996.

TABELA 1 - Altura; diâmetro de caule; número de folhas; matéria seca de raiz e da parte aérea de mudas de aceroleira adubadas com fósforo e zinco. Lavras-MG, 1996.

\begin{tabular}{|c|c|c|c|c|c|}
\hline$\underbrace{\text { Parâmetro }}_{\text {Tratamento }}{ }^{*}$ & $\begin{array}{c}\text { Altura } \\
(\mathrm{cm})\end{array}$ & $\begin{array}{l}\text { Diâmetro de } \\
\text { caule (mm) }\end{array}$ & $\begin{array}{l}\text { Número } \\
\text { de folhas }\end{array}$ & $\begin{array}{c}\text { Matéria } \\
\text { seca de raiz } \\
(\mathrm{g})\end{array}$ & $\begin{array}{l}\text { Matéria seca da } \\
\text { parte aérea }(\mathrm{g})\end{array}$ \\
\hline Testemunha & $12,15^{* *}$ & 2,82 & 13,0 & 0,24 & 0,84 \\
\hline $0 \mathrm{mg} \mathrm{dm}^{-3} \mathrm{de} \mathrm{P}+5 \mathrm{mg} \mathrm{dm}^{-3}$ de $\mathrm{Zn}$ & 15,50 & 2,87 & 11,0 & 0,27 & 1,04 \\
\hline $0 \mathrm{mg} \mathrm{dm}^{-3} \mathrm{de} \mathrm{P}+10 \mathrm{mg} \mathrm{dm}^{-3} \mathrm{de} \mathrm{Zn}$ & 23,50 & 3,55 & 30,0 & 0,72 & 2,75 \\
\hline $150 \mathrm{mg} \mathrm{dm}^{-3} \mathrm{de} \mathrm{P}+0 \mathrm{mg} \mathrm{dm}^{-3} \mathrm{de} \mathrm{Zn}$ & 26,50 & 3,62 & 37,0 & 0,56 & 2,48 \\
\hline $150 \mathrm{mg} \mathrm{dm}^{-3} \mathrm{de} \mathrm{P}+5 \mathrm{mg} \mathrm{dm}^{-3} \mathrm{de} \mathrm{Zn}$ & 26,20 & 3,77 & 37,0 & 0,79 & 3,48 \\
\hline $150 \mathrm{mg} \mathrm{dm}^{-3} \mathrm{de} \mathrm{P}+10 \mathrm{mg} \mathrm{dm}^{-3} \mathrm{de} \mathrm{Zn}$ & 29,90 & 4,50 & 47,0 & 1,45 & 3,95 \\
\hline $300 \mathrm{mg} \mathrm{dm}^{-3} \mathrm{de} \mathrm{P}+0 \mathrm{mg} \mathrm{dm}^{-3} \mathrm{de} \mathrm{Zn}$ & 23,0 & 3,71 & 29,0 & 0,90 & 2,74 \\
\hline $300 \mathrm{mg} \mathrm{dm}^{-3} \mathrm{de} \mathrm{P}+5 \mathrm{mg} \mathrm{dm}^{-3} \mathrm{de} \mathrm{Zn}$ & 33,37 & 4,66 & 70,0 & 1,97 & 6,42 \\
\hline $300 \mathrm{mg} \mathrm{dm}^{-3} \mathrm{de} \mathrm{P}+10 \mathrm{mg} \mathrm{dm}^{-3} \mathrm{de} \mathrm{Zn}$ & 25,50 & 4,25 & 27,0 & 0,86 & 3,04 \\
\hline $450 \mathrm{mg} \mathrm{dm}^{-3} \mathrm{de} \mathrm{P}+0 \mathrm{mg} \mathrm{dm}^{-3} \mathrm{de} \mathrm{Zn}$ & 33,50 & 4,66 & 70,0 & 1,90 & 6,67 \\
\hline $450 \mathrm{mg} \mathrm{dm}^{-3} \mathrm{de} \mathrm{P}+5 \mathrm{mg} \mathrm{dm}^{-3} \mathrm{de} \mathrm{Zn}$ & 33,10 & 4,29 & 50,0 & 1,41 & 5,47 \\
\hline $450 \mathrm{mg} \mathrm{dm}^{-3} \mathrm{de} \mathrm{P}+10 \mathrm{mg} \mathrm{dm}^{-3} \mathrm{de} \mathrm{Zn}$ & 27,00 & 3,97 & 39,0 & 1,00 & 3,94 \\
\hline
\end{tabular}

* Parâmetros apresentados e discutidos em outro artigo a ser publicado na RBF (artigo 303/01); ${ }^{* *}$ Valores médios de oito plantas

\section{CONCLUSÕES}

1. A interação entre os nutrientes fósforo e zinco afetou positivamente nos acúmulos de $\mathrm{Ca}, \mathrm{Cu}, \mathrm{Fe}$ e $\mathrm{Mn}$ na matéria seca de folhas de aceroleira, com um comportamento linear.

2. O nutriente zinco teve efeito positivo no acúmulo de zinco na matéria seca do caule.

3. O acúmulo dos demais nutrientes, na matéria seca de folha e caule, só foi influenciado pelo nutriente fósforo com a dose de $450 \mathrm{mg} \mathrm{dm}^{-3} \mathrm{de}$ P, proporcionou o maior acúmulo de todos os nutrientes na folha e caule, proporcionou também a obtenção de mudas aptas para o plantio, com altura superior a $33 \mathrm{~cm}$, e diâmetro do caule a $5 \mathrm{~cm}$ do solo acima de $4,00 \mathrm{~mm}$.

\section{REFERÊNCIASBIBLIOGRÁFICAS}

ALVES, R.N.B. Níveis de Nitrogênio, fósforo, potássio e magnésio para produção de porta-enxertos de seringueira (Hevea spp) no Amapá. 1987. 79f. Dissertação (Mestrado) - Escola Superior de Agricultura de Lavras, Lavras, 1987.

AMARAL, M.Q.G. do. Efeito de tipos de ramos sobre o enraizamento de estacas de acerola (Malpighia glabra L.) em diferentes substratos. 1992. 36f. Monografia (Graduação) - Escola Superior de Agricultura de Mossoró, Mossoró,1992.

BARBOSA, Z. Efeito do fósforo e do zinco na nutrição e crescimento de Myracrodruon urundeuva Fr. All. (Aroeira-do-Sertão). 1994. 105f. Dissertação (Mestrado em Solos e Nutrição de Plantas) - Universidade Federal de Lavras, Lavras, 1994.

CAMPOS, E. A. Efeito da adição do boro e zinco e substrato no desenvol- 
vimento de mudas de cafeeiro (Cofea arabica L.). 1980. 72 f. Dissertação (Mestrado em Fitotecnia ) - Escola Superior de Agricultura de Lavras, Lavras, 1980.

GONZAGA NETO, L.; SOARES. J.M. Acerola para exportação: aspectos técnicos da produção. Brasília: Embrapa-SPI/FRUPEX, 1994. 43p. (Série Publicações Técnicas, 10).

MACHADO, R.A.F. Fósforo e zinco na nutrição e crescimento de mudas de maracujazeiro-amarelo (Passiflora edulis f. flavicarpa Deg.). 1998. 93f. Dissertação (Mestrado em Fitotecnia) - Universidade Federal de Lavras, Lavras, 1998.

MALAVOLTA, E. Elementos de nutrição mineral de plantas. São Paulo. Ceres, 1980. 251p.

MALAVOLTA, E.; VITTI, G.C.; OLIVEIRA, S. A. Avaliação do estado nutricional das plantas: princípios e aplicações. Piracicaba: POTAFOS, 1989. 201p.

MARQUES, R. Efeitos do fósforo e zinco na nutrição e crescimento de porta-enxertos de seringueiras (Hevea brasiliensis Muell. Arg.). 1990. 110f. Dissertação (Mestrado em Solos e Nutrição de Plantas) Escola Superior de Agricultura de Lavras, Lavras, 1990.

MARTY, G.M.; PENNOCK, W. Práticas agronómicas para el cultivo comercial de la acerola em Puerto Rico. Revista de Agricultura de Puerto Rico, San Juan, v.52, p.107-111, 1965

OLSEN, S.R. Micronutrient Interaction. In: MORTVEDT, J.J.; GIORDANO, P.M.; LINDSAY, W.L. (Eds.) Micronutrients in
Agriculture. Madison: Soil Science Society of America, 1972. p.243264.

OLIVEIRA, P.R.A. Efeito do fósforo e zinco na nutrição e crescimento de mudas de mamoeiro e mangabeira. 2000. 184f. Tese (Doutorado em Fitotecnia) - Universidade Federal de Lavras, Lavras, 2000.

PASS, P.J. da. Crescimento de mudas enxertadas de seringueira (Havea spp) nas condições de sombra e a pleno sol em função da adubação nitrogenada e potássica, na presença e ausência da fosfatada e de ácido giberélico em solo podizólico variação Marilia. 1989. $140 \mathrm{f}$. Tese (Doutorado em Fitotecnia) - Escola Superior de Agricultura de Lavras, Lavras, 1989.

PEIXOTO, J.R. Efeito da matéria orgânica, superfosfato simples e do cloreto de potássio na formação de mudas de maracujazeiro-amarelo (Passiflora edulis Sims). 1986. 101f. Tese (Doutorado em Fitotecnia) - Escola Superior de Agricultura de Lavras, Lavras, 1986.

QUAGGIO, J.A. Critérios para calagem em solos do Estado e São Paulo. 1983. 86f. Tese (Mestrado em Solos e Nutrição de Plantas) - Escola Superior de Agricultura Luís de Queiroz, Piracicaba, 1983.

SIMÃO, S. Manual de fruticultura. São Paulo: Ceres, 1971.530p

TITTOTO, K.; SILVA, M.N.da; MONICA, I. Acerola: produção e mercado mundial. In: CONGRESSO BRASILEIRO DE FRUTICULTURA. 15., 1998, Poços de Caldas, MG. Anais... Poços de Caldas: SBF, 1998. p.68. 